\title{
A METHOD FOR THE SEPARATION OF RHODIUM FROM IRIDIUM AND THE GRAVIMETRIC DETERMINATION OF THESE METALS
}

\author{
By Raleigh Gilchrist
}

ABSTRACT

A method is described for the analytical separation of rhodium from iridium by means of titanous chloride. Two precipitations of the rhodium, as metal, from a solution of its sulphate in sulphuric acid were found to be sufficient to separate it completely from iridium. Following the separation, methods are described for the determination of rhodium by precipitation with hydrogen sulphide, for the elimination of titanium by precipitation with cupferron, and for the determination of iridium by hydrolytic precipitation.

An alternative method is offered in which rhodium and iridium are determined together in one sample by hydrolytic precipitation, and rhodium separately in a second sample.

\section{CONTENTS}

Page

I. Introduction

II. Compounds used in the experiments

III. Determination of iridium by hydrolytic precipitation

IV. Method recommended for the separation of rhodium from iridium and for the determination of these metals

1. Preparation of the solution

2. Separation and determination of rhodium

3. Recovery and determination of iridium

V. Discussion of the method.

\section{INTRODUCTION}

The separation of rhodium from iridium has long remained one of the most difficult of the analytical problems of the platinum group of metals. Berzelius, ${ }^{1}$ in a general scheme for the analysis of crude platinum, used molten potassium bisulphate to separate these two metals from one another. This method is unsatisfactory because of the incomplete removal of rhodium and the partial solution of iridium.

Another method, which is in current use, was employed by Claus, ${ }^{2}$ and by Leidie ${ }^{3}$ in schemes for the analysis of crude platinum. In these schemes the separation is based upon the precipitation of quadrivalent iridium as ammonium chloroiridate by ammonium chloride. Experience in this laboratory with the purification of the platinum metals has shown that rhodium contaminates iridium, when the latter is precipitated as ammonium chloroiridate, and that it can be eliminated only with great difficulty, if at all, by repeated precipitation of the iridium. Furthermore, since ammonium chloroiridate has a slight solubility, some of the iridium must remain with the rhodium. 
In a recent article, Ogburn and Miller ${ }^{4}$ proposed a method for the determination of osmium in which strychnine sulphate, $\mathrm{C}_{21} \mathrm{H}_{22} \mathrm{O}_{2} \mathrm{~N}_{2}-$ $\mathrm{H}_{2} \mathrm{SO}_{4}$, is used as a precipitating reagent. Attempts were made to determine whether this reagent could be used to effect the separation of iridium from rhodium. The reactions of strychnine sulphate with solutions of the quadrivalent platinum metal chlorides were observed. In each case a precipitate was obtained. No precipitate was obtained in chloride solutions of tervalent rhodium, tervalent iridium, or tervalent ruthenium (quadrivalent ruthenium chloride which had been heated with alcohol). In its reaction with the quadrivalent chlorides, the strychnine salt appears to behave like an ammonium salt, but with the production of compounds of much lower solubility.

It was found possible to precipitate iridium completely from solutions of ammonium chloroiridate in diluted hydrochloric acid $(5+95) .^{5}$ The reagent, moreover, caused no precipitation of rhodium from similarly acidified solutions of pure rhodium chloride. However, when strychnine sulphate was added to solutions containing both iridium and rhodium as chlorides, the iridium was found to be contaminated by rhodium to the extent of from 10 to 37 per cent of the rhodium present in the solutions. It was found possible to redissolve the iridium precipitate by treatment with nitric acid or with sodium nitrite, but it was not found possible to treat the solution in such a way as to permit the quantitative reprecipitation of the compound.

Wada and Nakazono, ${ }^{6}$ while studying the behavior of titanous sulphate toward various elements, observed that this reagent caused complete precipitation of metallic rhodium from solutions of its chloride, whereas iridium was not precipitated from its chloride solution. Apparently, the effect of the reagent on solutions containing both rhodium and iridium was not studied.

Attempts, in this laboratory, ${ }^{7}$ to use the foregoing reactions as a method of separation showed that the precipitated rhodium was contaminated with as much as 10 per cent of the iridium present. In the absence of any known means of redissolving the precipitate and thus preparing it for a second precipitation, the best that could be done was to fuse the ignited metal with pyrosulphate, in order to extract the rhodium. It was found that a small amount of iridium passed into solution and that the residues from the pyrosulphate fusions always retained some rhodium. The method, therefore, could not be made strictly quantitative but, in spite of its shortcomings, it was better than any other known procedure. The objects of the work described in this paper were to develop this method of separation into a strictly quantitative one and to provide suitable methods for the determinations of the two metals after they had been separated.

\section{COMPOUNDS USED IN THE EXPERIMENTS}

The iridium and the rhodium which were used throughout the investigation were purified by methods previously described ${ }^{8}$ and were found to be free from impurities by spectrographic analysis.

4 S. C. Ogburn, jr., and L. F. Miller, J. Am. Chem. Soc., vol. 52, p. 42, 1930.

5 This denotes 5 volumes of hydrochloric acid, specific gravity, 1.18, mixed with 95 volumes of water. This system of designating diluted acids is used throughout this paper. If no dilution is specified, the concentrated reagent is intended. The concentrated sulphuric acid used had a specific gravity of 1.84 .

6 I. Wada and T. Nakazono, Sci. papers Inst. Phys. Chem. Research, Japan, vol. 1, p. 139, 1923.

7 Unpublished work by W. H. Swanger and by H. A. Buchheit.

8 E. Wichers, R. Gilchrist, and W. H. Swanger, Trans. Am. Inst. Mining Met. Eng., vol. 76, p. 602, 1928. 
In order to avoid errors incident to volumetric measurements, weighed portions of the compounds, ammonium chloroiridate and ammonium chlororhodite, were used. Care was taken to avoid the presence of alkali chloride or of other nonvolatile impurities in the salts, but no attempt was made to prepare compounds of definite composition. The salts were carefully mixed by grinding in an agate mortar and the metallic content determined by direct ignition in hydrogen whenever a series of samples was weighed. It was never calculated from the theoretical composition of the salt.

\section{DETERMINATION OF IRIDIUM BY HYDROLYTIC PRECIPITATION}

By far the most difficult phase of the problem under consideration was that which dealt with the determination of the iridium after its separation from rhodium by tervalent titanium. Since the solution at this stage contains the titanium which has been added, it is necessary to effect a separation of the iridium from titanium. The most direct way to do this is to precipitate the iridium by hydrogen sulphide. ${ }^{9}$ Certain difficulties were encountered in an attempt to use hydrogen sulphide, such as incomplete precipitation of iridium and partial hydrolysis of titanium compounds, even though considerable quantities of tartaric acid were added to the solutions. The deposition of titanium dioxide was particularly noticeable on the walls of the beaker just above the level of the solutions. The titanium dioxide often formed an adherent mirror on the glassware. It likewise contaminated the sulphide precipitate and could be removed later only by fusion with bisulphate. The recovery of iridium by hydrogen sulphide will undoubtedly have many advantages when the proper conditions of control have been fully established. For the present, however, it seemed expedient to consider some other means by which the iridium could be recovered.

Preliminary experiments showed that the titanium could be entirely eliminated by precipitation with cupferron (ammonium salt of nitrosophenylhydroxylamine, $\mathrm{C}_{6} \mathrm{H}_{5} \mathrm{~N} \cdot \mathrm{NO} \cdot \mathrm{ONH}_{4}$ ). It was found that the small quantity of iridium, of the order of $1 \mathrm{mg}$ or less, which contaminated the first cupferron precipitate, was completely recovered by reprecipitating the titanium.

Previous work on the determination of ruthenium ${ }^{10}$ and of osmium ${ }^{11}$ by hydrolytic precipitation suggested that a similar method was feasible for iridium. Sodium bicarbonate was added to boiling aqueous solutions of ammonium chloroiridate until the color became green. Sodium bromate was then added and the solutions were boiled for 25 minutes to coagulate the finely divided precipitate and to insure complete precipitation. The greenish-black precipitates were treated as described in the procedure given later. The acidities of the filtrates from the hydrolytic precipitation were determined approximately by means of indicator solutions. In four of the solutions from which complete recovery of the iridium was obtained, the acidities ranged from $\mathrm{pH} 4$ to $\mathrm{pH} 4.6$. In the fifth filtrate the $\mathrm{pH}$

- This method of recovery of iridium has certain advantages which make it of importance in the analytical chemistry of the platinum group. While the exact conditions which will allow complete precipitation of iridium have not yet been fully established, further work is being done and will appear later in the description of a general method for the separation of the platinum group.

${ }_{10}$ Gilchrist, B. S. Jour. Research, vol. 3, p. 993, 1929.

11 Gilchrist, B. S. Jour. Research, vol. 6, p. 421, 1931. 
value was somewhere between 1.5 and 4 . This filtrate was found to contain a small quantity of iridium.

In order to establish proper conditions for the iridium precipitation, it became necessary to be able to detect small amounts of iridium in the filtrates from the hydrolytic precipitations. A test which has been frequently employed in this laboratory consists in the development of a green or blue color ${ }^{12}$ when a concentrated solution of sulphuric acid, containing iridium, is heated with nitric acid. With quantities of iridium less than $0.1 \mathrm{mg}$, the color developed is green, with larger amounts it is blue. A few precautions, however, must be observed. Chlorides appear to decompose the particular compound responsible for the blue color. The sulphuric acid, therefore, must be heated until heavy vapors are evolved and this treatment repeated, after the addition of a small quantity of nitric acid, until all hydrochloric acid is expelled. Furthermore, the strongly acid solution must not be heated for too long a time after the last addition of nitric acid. If these two precautions are observed, the color will often remain visible for as long as a week. The test is likewise applicable when considerable quantities of alkali sulphates are present. If the composition of the evaporated solution be made to approximate that of sodium bisulphate, with a slight excess of sulphuric acid, the color of the salt on solidification will often remain visible for several weeks, changing slowly from blue to violet with the absorption of water from the air. The limiting quantity of iridium capable of certain detection, under the conditions mentioned above, appeared to be $0.1 \mathrm{mg}$.

The results of the determination of iridium by hydrolytic precipitation from aqueous solutions of ammonium chloroiridate are given in Table 1. The error in No. 12 is ascribed to the fact that the solution was too acid.

TABLE 1.-Recovery of iridium from aqueous solutions of ammonium chloroiridate by hydrolytic precipitation

\begin{tabular}{|c|c|c|c|c|c|c|}
\hline No. & $\begin{array}{l}\left(\mathrm{NH}_{4}\right)_{2} \\
\text { IrCl } \\
\text { taken } \\
42.69 \mathrm{per} \\
\text { cent Ir }\end{array}$ & $\begin{array}{l}\text { Iridium } \\
\text { present }\end{array}$ & $\begin{array}{l}\text { Iridium } \\
\text { recovered }\end{array}$ & Error & $\begin{array}{c}\mathrm{pH} \text { of } \\
\text { filtrate }\end{array}$ & $\mathrm{H}_{2} \mathrm{SO}_{4}-\mathrm{HNO} \mathrm{HN}_{3}$ test of filtrate \\
\hline 10 & $\begin{array}{l}g \\
0.1850 \\
.2210 \\
.2602 \\
.3121 \\
.1869\end{array}$ & $\begin{array}{l}g \\
0.0790 \\
.0943 \\
.1111 \\
.1332 \\
.0798\end{array}$ & $\begin{array}{l}g \\
0.0790 \\
.0931 \\
.1112 \\
.1332 \\
.0798\end{array}$ & $\begin{array}{r}g \\
0.0000 \\
-.0012 \\
+.0001 \\
.0000 \\
.0000\end{array}$ & $\begin{array}{l}14 \\
1.5-4 \\
4.3-4.5 \\
14 \\
14.6\end{array}$ & $\begin{array}{l}\text { Very faint. Greenish color. } \\
\text { Deep blue. } \\
\text { Colorless. } \\
\text { Do. } \\
\text { Do. }\end{array}$ \\
\hline
\end{tabular}

1 Approximately.

Since the solution from which the iridium must be recovered after the elimination of titanium will contain a considerable quantity of sulphuric acid, it was necessary to establish the conditions for precipitating iridium from such a solution. Solutions of iridium in 10 $\mathrm{ml}$ of sulphuric acid were prepared according to directions given later in the section on recommended procedure. These solutions were diluted with $20 \mathrm{ml}$ of water and $10 \mathrm{ml}$ of hydrochloric acid and boiled for 15 minutes. The solutions were then further diluted, filtered, and

${ }^{12}$ Fresenius, T. W., Qualitative Chemical Analysis (John Wiley \& Sons, New York, N. Y.), English translation of 17 th German ed. by C. Ainsworth Mitchell, 1921, p. 377. 
almost neutralized with a solution of sodium bicarbonate. A considerable quantity of sodium bicarbonate was required (approximately $30 \mathrm{~g}$ ), but this caused no difficulty in the precipitation. The desired end point ( $\mathrm{pH} 4$ ), in the addition of the sodium bicarbonate solution, was indicated by the appearance of a blue color when a drop of brom phenol blue solution (0.04 per cent) was allowed to run down the stirring rod to which clung a drop of the boiling solution. The presence of bromate made the above manner of testing the only one feasible. The solutions were boiled for 25 minutes and filtered. The precipitates were treated as directed in the section on recommended procedure.

The results of the determination of iridium by hydrolytic precipitation at $\mathrm{pH} 4$ from solutions strongly acid with sulphuric acid and hydrochloric acid are given in Table 2 . The incomplete precipitation in Nos. 56 and 57 is ascribed to the fact that the desired end point was not quite reached.

TABLE 2.-Recovery of iridium from solutions of iridium sulphate in sulphuric acid by hydrolytic precipitation

\begin{tabular}{|c|c|c|c|c|c|}
\hline No. & $\begin{array}{c}\left(\mathrm{NH}_{4}\right)_{2} \mathrm{IrCl}_{6} \\
\text { taken } \\
42.70 \text { per } \\
\text { cent Ir }\end{array}$ & $\begin{array}{c}\text { Iridium } \\
\text { present }\end{array}$ & $\underset{\text { recovered }}{\text { Iridium }}$ & Error & $\mathrm{H}_{2} \mathrm{SO}_{4}-\mathrm{HNO}_{3}$ test of filtrate \\
\hline $\begin{array}{l}56 \\
57 \\
58 \\
24\end{array}$ & $\begin{array}{l}g \\
0.4139 \\
.3297 \\
.4029 \\
.3510\end{array}$ & $\begin{array}{l}g \\
0.1767 \\
.1408 \\
.1720 \\
.1499\end{array}$ & $\begin{array}{c}g \\
0.1762 \\
.1403 \\
.1721 \\
.1501\end{array}$ & $\begin{array}{r}g \\
-0.0005 \\
-.0005 \\
+.0001 \\
+.0002\end{array}$ & \multirow{3}{*}{$\begin{array}{l}\text { Faint bluish color. } \\
\text { Do. } \\
\text { No iridium detected. } \\
\text { Faint greenish color, not more than } 0.2 \\
\text { mg Ir. } \\
\text { Very faint greenish color, not more than } \\
0.1 \mathrm{mg} \text { Ir. } \\
\text { Do. }\end{array}$} \\
\hline 28 & .3410 & .1456 & .1457 & +.0001 & \\
\hline $32 \ldots$ & .4128 & .1763 & .1764 & +.0001 & \\
\hline
\end{tabular}

While it was found that iridium was completely precipitated from solution by hydrolysis at $\mathrm{pH} 4$ in the presence of bromate, it was desirable to learn whether the precipitation was quantitative over a range of $\mathrm{pH}$ values and whether the addition of bromate was essential. It was found that precipitation at $\mathrm{pH} 6$ was quantitative and that a shorter time of boiling, 10 minutes, was sufficient, provided bromate was present. Solutions of iridium which had been merely saturated with chlorine failed to yield complete precipitation. Solutions of iridium, which had been evaporated with nitric acid and subsequently with hydrochloric acid, turned green at $\mathrm{pH} 6$ and did not yield complete precipitation without the addition of bromate. In connection with this last-named treatment, it was found that the previous addition of nitric acid did not prevent the precipitation of iridium as it does in the case of ruthenium. ${ }^{13}$

\section{METHOD RECOMMENDED FOR THE SEPARATION OF RHODIUM FROM IRIDIUM AND FOR THE DETERMINA- TION OF THESE METALS}

\section{PREPARATION OF THE SOLUTION}

Place the solution containing the rhodium and iridium as chlorides in a $500 \mathrm{ml}$ Erlenmeyer flask, closed with a short-stemmed funnel. Add $10 \mathrm{ml}$ of sulphuric acid and 2 to $3 \mathrm{ml}$ of nitric acid and evaporate 
until heavy vapors of sulphuric acid are evolved. Add several portions of nitric acid from time to time and continue to heat over a free flame, keeping the solution in constant motion. Dilute the cooled solution with $20 \mathrm{ml}$ of water and again evaporate until vapors of sulphuric acid appear. This is done to destroy nitroso compounds which may interfere in the precipitation of rhodium by titanous chloride.

\section{SEPARATION AND DETERMINATION OF RHODIUM}

Transfer the solution to a clean, unetched beaker, dilute it to 200 $\mathrm{ml}$, and heat it to boiling. Add dropwise a solution of titanous chloride (a 20 per cent solution of this reagent may be purchased) until the supernatant liquid appears slightly purple. If the solution is placed over a 100-watt light and stirred, observation of the end point is greatly facilitated. Boil the solution for two minutes and filter it. Wipe the walls of the beaker and also the stirring rod with a piece of ashless filter paper. Wash the filter and precipitated metal thoroughly with cold diluted sulphuric acid $(2.5+97.5)$. Place the filter and contents in a $500 \mathrm{ml}$ Erlenmeyer flask, add $10 \mathrm{ml}$ of sulphuric acid, char gently, then heat the solution until vapors of sulphuric acid appear. Destroy the organic matter with nitric acid. Fuming nitric acid is preferable to the ordinary concentrated acid. If solution of the rhodium is not complete, that is, if some black specks remain unattacked, dilute the solution, filter it and return the filter to the flask. Wipe down the walls of the flask with a piece of ashless filter paper. Add $5 \mathrm{ml}$ of fresh sulphuric acid, char the paper and destroy all organic matter with nitric acid. Heat the solution until heavy vapors of sulphuric acid are evolved. This treatment will insure complete solution of any remaining metal and will leave only a slight deposit of colorless silica.

Precipitate the rhodium a second time in the manner described above. Redissolve the rhodium as before, dilute the sulphuric acid solution with $20 \mathrm{ml}$ of water and $10 \mathrm{ml}$ of hydrochloric acid and boil the resulting solution for 15 minutes. This treatment is necessary to convert the rhodium to a form which will allow complete precipitation by hydrogen sulphide. Dilute the solution, now rose colored. Filter it and precipitate the rhodium by hydrogen sulphide from a boiling solution having a volume of from 400 to $500 \mathrm{ml}$. Filter the solution and wash the sulphide precipitate with cold diluted sulphuric acid $(2.5+97.5)$ and finally with water. Place the filter with the sulphide precipitate in a porcelain crucible. Ignite the dried precipitate carefully in air. Ignite the oxidized residue in hydrogen, cool in hydrogen, and weigh as metallic rhodium.

\section{RECOVERY AND DETERMINATION OF IRIDIUM}

Dilute the combined filtrates from the precipitation of rhodium by titanous chloride to $800 \mathrm{ml}$. Cool the solution by placing the beaker in crushed ice. Add a chilled, filtered, freshly prepared solution of cupferron (6 per cent) in slight excess. Add some filter paper pulp, filter by suction and wash the titanium precipitate with chilled diluted sulphuric acid $(2.5+97.5)$ containing some cupferron. The paper pulp is added to prevent the precipitate from becoming too densely packed. Return the precipitate to the beaker and add 
nitric acid until the compound is mostly decomposed. Add $20 \mathrm{ml}$ of sulphuric acid and heat until vapors of sulphuric acid appear. Destroy all organic matter with nitric acid. Dilute the resulting solution to $800 \mathrm{ml}$ and repeat the precipitation of the titanium. The first cupferron precipitate will usually be contaminated by about $1 \mathrm{mg}$ or less of iridium. Unite the two filtrates from the cupferron precipitations and evaporate until approximately $10 \mathrm{ml}$ of sulphuric acid remains. Insure the destruction of all organic matter by adding nitric acid. Dilute the sulphuric acid solution with $20 \mathrm{ml}$ of water and $10 \mathrm{ml}$ of hydrochloric acid and boil the resulting solution for 15 minutes. Dilute the solution somewhat, filter it, and precipitate the iridium by hydrolysis. To do this, add a filtered solution of sodium bicarbonate until the acidity of the solution reaches a value of $\mathrm{pH} 6$. Since the color of the solution will, in general, mask the color of the indicator, it is necessary to make the test on a drop of the solution clinging to the stirring rod. If a drop of brom cresol purple indicator solution ( 0.04 per cent) is colored faintly blue when it comes in contact with the drop of solution on the stirring rod, the solution possesses an acidity which will allow complete precipitation of the iridium. At this point, add $20 \mathrm{ml}$ of a 10 per cent solution of sodium bromate and boil the solution for 20 to 25 minutes. Make sure, however, that sufficient bromate is present to oxidise all of the iridum to the quadrivalent state. Filter the solution and wash the precipitate thoroughly with a hot 1 per cent solution of ammonium chloride. Place the filter and precipitate of hydrated iridium dioxide in a porcelain crucible. Dry somewhat and moisten the contents of the crucible with a saturated solution of ammonium chloride. This is done to prevent deflagration of the hydrated dioxide on subsequent ignition in air. Ignite the filter and precipitate in air and then in hydrogen. Leach the metallic residue with diluted hydrochloric acid $(1+5)$, transfer it to a filter and wash it with hot water. This precaution is taken to insure complete removal of soluble salts. Ignite the metallic residue in air. Finally, ignite the resulting oxidised metal in hydrogen, cool in hydrogen and weigh as metallic iridium.

The results of the determination of rhodium and of iridium, obtained by following the procedure of separation and of recovery which has just been outlined, with the exception that the iridium was precipated at $\mathrm{pH} 4$, are given in Table 3. The result of one experiment, in which rhodium was twice precipitated by titanous chloride in the absence of iridium, is also included.

TABLE 3.-Results of the analysis of solutions containing both rhodium and iridium

\begin{tabular}{|c|c|c|c|c|c|c|c|c|}
\hline No. & $\begin{array}{c}\left(\mathrm{NH}_{4}\right)_{3} \\
\mathrm{RhCl} \\
\text { taken } \\
30.48 \mathrm{per} \\
\text { cent Rh }\end{array}$ & $\begin{array}{c}\text { Rhodium } \\
\text { present }\end{array}$ & $\begin{array}{l}\text { Rhodium } \\
\text { recovered }\end{array}$ & Error & $\begin{array}{c}\left(\mathrm{NH}_{4}\right)_{2} \\
\text { IrClo } \\
\text { taken } \\
42.70 \text { per } \\
\text { cent Ir }\end{array}$ & $\begin{array}{l}\text { Iridium } \\
\text { present }\end{array}$ & $\underset{\text { recovered }}{\text { Iridium }}$ & Error \\
\hline & 0 & $g_{0556}^{g}$ & $0_{0.0556}^{g}$ & $\stackrel{g}{0} 0000$ & $g$ & $g$ & $g$ & $g$ \\
\hline & .1478 & .0451 & .0451 & .0000 & 0.1722 & 0.0735 & . & \\
\hline & $\begin{array}{l}.4444 \\
.4732\end{array}$ & $\begin{array}{r}.1355 \\
.1442\end{array}$ & $\begin{array}{r}.1354 \\
.1442\end{array}$ & $\begin{array}{r}-.0001 \\
.0000\end{array}$ & $\begin{array}{l}.2584 \\
.3309\end{array}$ & $\begin{array}{r}.1103 \\
.1413\end{array}$ & 0.1412 & -0.0001 \\
\hline & .3991 & .1216 & .1215 & -.0001 & .3804 & .1624 & .1622 & -.0002 \\
\hline & .2757 & .0840 & .0838 & -.0002 & .3092 & . 1320 & .1320 & \\
\hline
\end{tabular}

Note.-A very faint greenish color was produced when the filtrates from the hydrolytic precipitation of iridium in Nos. 66-54 and 67-55 were tested for iridium. No iridium was detected in the filtrate from No. $14-43$. 
To make certain that the second precipitation by cupferron sufficed to separate all of the iridium from the titanium, the second cupferron precipitates were redissolved and the titanium reprecipitated. No trace of iridium was found in the filtrates from the third precipitation of the titanium, nor in the solutions of the third precipitates themselves.

The filtrates from the hydrolytic precipitations of the iridium were likewise tested. A small amount of iridium, not exceeding $0.1 \mathrm{mg}$, was found in the filtrates from Nos. 66-54 and 67-55.

The chemical examination of the recovered iridium for traces of rhodium is extremely difficult, as no sensitive test for rhodium is known. From the fact that rhodium was found to be completely precipitated by titanous chloride from pure solutions of rhodium and from the fact that the quantities of rhodium recovered from actual separation were identical with the quantities taken, it is reasonable to conclude that no significant amount of rhodium contaminated the recovered iridium.

The chemical examination of the separated rhodium for traces of iridium is simple because a sensitive test for iridium exists. A quantity of iridium, 0.1 to $0.2 \mathrm{mg}$, is sufficient to give a greenish cast to the yellow solution of rhodium in concentrated sulphuric acid. Since no iridium was detected either in the solutions of the rhodium which had been precipitated twice by titanous chloride or in the filtrates from the hydrogen sulphide precipitation of the rhodium, it was concluded that the recovered rhodium was not contaminated by iridium.

\section{DISCUSSION OF THE METHOD}

In the early experiments on the separation of rhodium from iridium the first precipitation was made from solutions of rhodium and iridium chlorides in diluted sulphuric acid $(5+95)$ at room temperature. A considerable excess of titanous chloride was added and the solutions were filtered after definite periods of time. The precipitated metal was finely divided and partially passed through the filters. It was very difficult to observe the filtrates for escaped metal because of the intense color of the reagent. The large excess of titanous chloride appeared to cause the deposition of too great a proportion of the iridium. The deposition of iridium was even more pronounced when the solutions were heated in an attempt to coagulate the precipitates. Inasmuch as reprecipitation of the rhodium had to be made from a solution of the metal sulphates in diluted sulphuric acid, because of the method used to redissolve the precipitate, the first precipitation was also made from a similar solution in the later experiments. When both precipitations were made from a boiling solution of the metal sulphates and only a very slight excess of titanous chloride was added, it was found that the second precipitation of the rhodium completely eliminated the last trace of iridium.

Although the other four platinum metals must be absent at this stage of the general analysis, it was, nevertheless, desirable to know how they behaved toward titanous chloride. The reagent was added to solutions containing approximately $50 \mathrm{mg}$ of each metal in $100 \mathrm{ml}$ of diluted hydrochloric acid $(5+95)$ at room temperature. Palladium 
appeared to be precipitated immediately and platinum almost inımediately. The brown color of ruthenium chloride was changed to deep blue, but no precipitation occurred when the solution was allowed to stand for one week. No precipitation occurred with a solution of chloroosmic acid even when it was allowed to stand for three weeks.

When solutions of rhodium, or of rhodium and iridium, are heated to heavy vapors of sulphuric acid, precaution must be taken to prevent the formation of insoluble compounds by local superheating. The formation of such compounds is easily avoided by keeping the hot sulphuric acid solution in constant motion.

The essential feature which makes the scheme proposed by Wada and Nakazono workable is a method by which the precipitated rhodium can be redissolved. A few comments regarding the technic of the operation appear worthy of emphasis. An Erlenmeyer flask should be used in preference to a beaker or to a Kjeldahl flask. With a beaker, there is danger of mechanical loss of material, particularly at the danger of mechanical loss of material, particularly at the stage where the last traces of moisture are being eliminated. The drops of condensed steam on the under side of the cover glass fall into the hot sulphuric acid and cause violent spattering. With a Kjeldahl flask, it is extremely difficult to wipe down the particles of undissolved metal from the walls. If this latter precaution is not observed, the results for the recoveries of rhodium will invariably be low by amounts up to about $1 \mathrm{mg}$.

The metallic rhodium, obtained in the second precipitation with titanous chloride, must not be ignited directly because it is always contaminated by silica, introduced through the titanous chloride and possibly from the glassware, and by a small amount of titanium. Consequently, the rhodium is again dissolved and precipitated by hydrogen sulphide. It was not found possible to precipitate the rhodium completely by hydrogen sulphide from solutions of the metal sulphate in sulphuric acid. This same difficulty has often been observed in this laboratory with solutions prepared by dissolving the product of bisulphate fusions of rhodium. A solution of the rhodium can be prepared, however, by adding diluted hydrochloric acid $(1+2)$, equal to three times the volume of the concentrated sulphuric acid solution, and boiling it. The yellow color of the sulphate solution then changes to rose red, which is the same as the characteristic color of rhodium chloride. No difficulty attends the precipitation of rhodium from the solution so treated.

The determination of rhodium and of iridium can be greatly simplified and the titanium precipitations avoided if the solution can be divided conveniently into aliquot parts. Incidental experiments showed that rhodium is completely precipitated as an olivegreen hydrated dioxide at $\mathrm{pH} 6$ when bromate is present. Since iridium is precipated quantitatively under the very same conditions, the two can be precipitated together and finally recovered as a metallic mixture. In addition, rhodium must be determined separately on a different portion by precipitation with titanous chloride in the manner described in the recommended procedure. 
The method which has been described in this paper is designed for the separation of rhodium from iridium and for the determination of these metals when other elements are absent. It will constitute a part of a general scheme for the analysis of the platinum group and will follow the procedures for the separation of osmium, ruthenium, platinum, and palladium.

Washington, July 11, 1932. 